\title{
A palavra, os discursos e a dinâmica das memórias
}

\author{
Anderson Salvaterra Magalhães ${ }^{a}$
}

\begin{abstract}
Resumo
Neste artigo, o objetivo é demonstrar, a partir de uma breve análise do processamento semiótico-dialógico de um vocábulo de sua gênese até o registro em verbete, como a palavra pode movimentar discursos que sustentam e são sustentados por valores constitutivos do grupo social que mobiliza a linguagem e, assim, introjetar, na memória da língua, não apenas formas linguísticas, mas também juízo, visão de mundo. De um ponto de vista dialógico de linguagem, argumenta-se que a lingua, na condição de sistema de signos ideológicos, é um construto sociocultural e, por isso, é interdependente do processo de formação de grupos sociais. A análise desenvolvida mostra que o léxico pode, por vezes, sinalizar, pela forma, a convergência linguística e, pelos discursos que mobiliza na contemporaneidade, pode, por outras vezes, apontar a distinção de vernáculos.
\end{abstract}

Palavras-chave: léxico; estudos bakhtinianos, dimensão ético-política e estética da linguagem.

a Universidade Federal de São Paulo, eumagalhaes@yahoo.com.br. 


\section{Considerações iniciais}

Este trabalho faz parte de uma investigação maior acerca da relação entre as tecnologias de memória cultural e os discursos constitutivos e mobilizadores de processos de construção, de critérios de validação e de modos de manifestação de laços e arranjos coletivos no cenário brasileiro, com ênfase na questão vernacular. Como já discutido em outro momento (MAGALHÃES, 2012; 2013, por exemplo), o senso de vernáculo no Brasil é gerado pela tensão linguístico-cultural deflagrada a partir da colonização europeia, em particular, lusitana, que, por um lado, concebe como ádvena a multiplicidade étnica, cultural, linguística que encontra e, por outro lado, projeta uma unidade política e territorial ao vasto e heterogêneo espaço geográfico. Assim, a construção de Brasil e do que é significado como próprio do Brasil estão necessariamente implicadas nessa tensão fomentadora de significados e sentidos, e a língua desempenha função preponderante nesse processo. Especificamente neste artigo, é focado o modo como o léxico pode corroborar a língua portuguesa do Brasil e atualizar discursos que a) são decisivos para a construção e consolidação do que pode ser chamado de brasilidade e b) permitem identificar a produtividade ideológica da memória da língua portuguesa no Brasil como língua portuguesa do Brasil. O objetivo é demonstrar, a partir de uma breve análise do processamento semiótico-dialógico de um vocábulo desde a gênese até o registro em verbete, como a palavra pode movimentar discursos que sustentam e são sustentados por valores constitutivos do grupo social que mobiliza a linguagem e, assim, introjetar, na memória da língua, não apenas formas linguísticas, mas também juízo, visão de mundo.

Para nortear a discussão, levanta-se a seguinte pergunta: como a memória da língua portuguesa no Brasil atualiza valores sociais que fomentam possibilidades de significação sociocultural do Brasil? A resposta para essa questão é apresentada em três etapas inter-relacionadas. Primeiro, é necessário discutir teoricamente a relação entre língua e organização social, especialmente entre o léxico, os discursos e as memórias que se mobilizam para pontuar o que entra em jogo no processo de significação e de construção de grupo social. Em seguida, justificam-se: a seleção do vocábulo botocudo como mote do estudo e os procedimentos para, a partir dele, recuperar a dinâ- 
1 Neste artigo, as referências, incluindo aquelas às fontes do pensamento bakhtiniano, são indicadas de acordo com as edições consultadas. Daí a diferença ortográfica entre Volochínov e Voloshinov, por exemplo. Especificamente para detalhamento acerca das condições de produção e circulação das fontes do pensamento bakhtiniano, verificar Emerson (2003). Para detalhamento acerca de sua recepção brasileira, verificar, entre outros títulos, Brait (2009a e 2009 b) e Brait \& Magalhães (2014). mica de memórias que atualiza o processo semiótico-ideológico decisivo para constituição de grupo(s) social(is) do Brasil. Por fim, é analisado dialógico-discursivamente o vocábulo atualizado em verbete de dicionário e em outros três enunciados de diferentes esferas - literária, política e jornalística - a fim de demonstrar como as acepções do dicionário documentam, para além da forma, valores sociais implicados na palavra e, dessa maneira, mobilizam discursos e fomentam a potencialidade semântica que integra a memória da língua.

\section{Língua(gem) e sociação: esboçando um dispositivo analítico para tensões vernáculas brasileiras}

Curiosamente, a relação entre léxico, memória e organização social pode parecer tanto evidente quanto estanque. Se, por um lado, soa contraintuitivo imaginar que a organização de grupo, sua linguagem e o repertório compartilhado não sejam implicados nem imbricados, por outro, qualquer análise desses aspectos esbarra no desafio interdisciplinar, o que sugere serem objetos distintos. De fato, são objetos distintos, porém, do ponto de vista dialógico aqui advogado, interdependentes. Para tratar dessa interdependência, vale retomar alguns pontos do pensamento de Bakhtin e o Círculo - com destaque para as noções de língua e memória da língua - e de Georg Simmel especificamente sua concepção de sociação.

A concepção de língua no pensamento de Bakhtin e o Círculo é tecida em, ao menos, dois movimentos argumentativos ao longo da obra dos pensadores russos. Por um lado, a partir da recepção, logo nas primeiras décadas do século $X X$, do Curso de Linguística Geral atribuído a Ferdinand de Saussure, a língua é pensada, ontologicamente, como fato social e, metodologicamente, como sistema de signos. Por outro lado, é também pensada a partir de diversas abordagens que, na classificação de Bakhtin/Volochínov (1999) ${ }^{1}$, podem ser definidas como subjetivistas e que operam com a dimensão de língua como expressão do indivíduo. Esses dois pontos de vista são mobilizados para a conceituação de língua num viés epistêmico que não opera com o antagonismo entre individual-subjetivo/social-coletivo, e sim com a articulação entre aspectos estáveis, mais permanentes, por assim dizer, e aspectos singulares, irrepetíveis da língua e da linguagem. Para localizar tal perspectiva teórica, vale 
resgatar brevemente - apenas um lampejo para não extrapolar o objetivo central deste artigo - os fundamentos do raciocinio dialógico que emerge da obra de Bakhtin e o Círculo.

Envolvidos em estudos kantianos desde os primórdios dos diferentes Círculos que organizariam depois (BRAIT; CAMPOS, 2009), os pensadores russos assimilam e reacentuam uma tradição epistêmica que distingue duas naturezas de conhecimento: a priori e a posteriori, sendo este derivado da experiência empírica e aquele independente de toda e qualquer experiência (KANT, 2004). Esses dois tipos de conhecimento relacionam-se no processo de conhecer que, de algum modo, implica dois planos: o da realidade empírica e subjetiva e o da abstração que independe do indivíduo. Como pontua o filósofo prussiano na revisitação de seu próprio texto,

[...] na ordem do tempo, nenhum conhecimento precede em nós a experiência e é com esta que todo o conhecimento se principia. Porém, se todo conhecimento se principia com a experiência, isso não prova que todo ele derive da experiência. Nosso próprio conhecimento experimental bem poderia ser um composto do que recebemos por meio das impressões sensíveis e daquilo que a nossa própria capacidade de conhecer - apenas acionada por impressões sensíveis - produz por si mesma, acréscimo esse que não distinguimos dessa matéria-prima, enquanto a nossa atenção não despertar por um longo exercício que nos capacite a separá-los. (KANT, 2004, p. 44).

Dessa perspectiva, é possível ponderar que, se há diferentes tipos de conhecimento, o processo de conhecer não necessariamente os separa, já que mobiliza a ambos. Existe algo no processo que lhe é facultado a priori, habilitado pela faculdade cognoscitiva e sem o qual o conhecimento a posteriori, resultante das experiências empíricas, seria comprometido. Essa reflexão kantiana influencia diretamente o pensamento bakhtiniano desde o primeiro ensaio filosófico de fôlego do pensador russo (BAKHTIN, 2010a). Conforme argumenta Amorim (2009a), naquele ensaio o jovem Bakhtin lança as bases filosóficas que elucidam o conjunto da obra que construiria e, por isso, funciona como texto prospectivo cujo projeto é praticamente concluído nos textos que o seguem. Assim, é pertinente entender alguns aspectos pontuados no ensaio como um exercício epistemológico. Entre os vários pontos 
relevantes, neste artigo, merece destaque a distinção e, ainda mais importante, a articulação que Bakhtin faz entre o mundo da cultura e o mundo da vida.

Segundo o pensador russo, no mundo da cultura está a verdade de validade universal (istina) que independe do sujeito para referendá-la (BAKHTIN, 2010a). Trata-se, por exemplo, da verdade da lei de Newton, que era válida do ponto de vista físico mesmo antes de ser descoberta pelo cientista (BAKHTIN, 2010a, p. 54). No mundo da cultura, estão a proposição teórica, o significado extratemporal, o juízo de validade universal, o aspecto abstrato do sentido e, por isso, o mundo da cultura é por vezes também denominado no conjunto da obra do Círculo mundo teórico, mundo do conhecimento ou mundo cognitivo. Em termos kantianos, é possível dizer que, no mundo da cultura, cabe o conhecimento a priori, uma vez que prescinde de qualquer vivência. Já no mundo da vida, está a verdade validada pelo sujeito (pravda), pelo indivíduo que a enuncia e, assim, assume a responsabilidade de dizê-la (BAKHTIN, 2010a). Este é o mundo da existência, do acontecimento, da vivência; o mundo do sentido espacial e temporalmente localizado no existir-evento singular e manifesto no aspecto emotivo-volitivo (relacionado à entoação da palavra) da enunciação (BAKHTIN, 2010a, p. 55, 84). Seguindo a inspiração kantiana, é possível afirmar que, no mundo da vida, está o conhecimento a posteriori, aquele implicado no sujeito e sua vivência.

A distinção de dois mundos no pensamento bakthiniano visa o alcance daquilo que elege como ponto nevrálgico a ser examinado: o ato ético responsável. A distinção do mundo da cultura e do mundo da vida é condição para a articulação de dois planos necessária à existência. Segundo Bakhtin, o sujeito não existe em sua vivência descolada do que é objetivado no mundo da cultura. Em contrapartida, o mundo da cultura só faz sentido na tensão com a vivência do sujeito. Aqui vale citar um trecho elucidativo do ensaio:

$\mathrm{O}$ ato da atividade de cada $\mathrm{um}$, da experiência que cada um vive, olha, como um Jano bifronte, em duas direções opostas: para a unidade objetiva de um domínio da cultura e para a singularidade irrepetível da vida que se vive, mas não há um plano unitário e único em que as duas faces se determinem reciprocamente em relação a uma unidade única. [...] $\mathrm{O}$ ato deve encontrar um único plano unitário para refletir-se em ambas as direções, no seu sentido e 
em seu existir; deve encontrar a unidade de uma responsabilidade bidirecional, seja em relação ao seu conteúdo (responsabilidade especial), seja em relação ao seu existir (responsabilidade moral), de modo que a responsabilidade especial deve ser um momento incorporado de uma única e unitária responsabilidade moral. Somente assim se pode superar a perniciosa separação e a mútua impenetrabilidade entre cultura e vida. (BAKHTIN, 2010a, p. 43-44).

Bakhtin elege o ato ético responsável como fronteira entre vivência e domínios da cultura e, de um modo ou de outro, o perseguirá ao longo de sua obra, sendo o conceito, portanto, condição para entendimento da questão que se levanta neste artigo. Isso porque os conceitos mobilizados da teoria que emerge da obra do Círculo devem se alinhar à noção de ato ético, para devida articulação entre o que tende ao estável e o que tende ao instável no funcionamento da linguagem, da língua e da sociedade.

Da perspectiva epistêmica advogada por Bakhtin e o Círculo - que aqui se sugere chamar de raciocínio dialógico -, a noção de língua, em parte, parece se coadunar, ontologicamente, com a concepção de fato social apresentada no Curso de Linguística Geral (SAUSSURE, 1995), mas não metodologicamente com a definição de língua como sistema de signos. Como assim? A orientação durkheimeana recuperada no Curso autoriza identificar na língua, como fato social, o caráter geral, que implica o compartilhamento de uma comunidade; o caráter extrínseco, que desvincula o fato social da volição do indivíduo; e o caráter coercitivo, que constrange os membros da comunidade à aceitação de padrões e normas implicados no fato. No raciocínio dialógico, a dimensão social, plural, coletiva inerente à concepção saussuriana de língua é válida. Até aí é possível identificar pontos de contato. Entretanto, para os pensadores russos, não há como cindir ideologia e semiotização, posto que o processamento semiótico requer um agrupamento social e vice-versa. Nesse caso, o indivíduo não figura como fronteira entre o universo singular interior e realidade objetiva exterior, mas sim como sujeito que, pela linguagem, integra a comunidade. Dessa perspectiva, sobretudo o caráter extrínseco previsto na orientação durkheimeana de fato social soa impertinente, já que a questão da volição não se 
coloca para o funcionamento linguístico nem a comunidade se define fora da linguagem. Isso propicia encaminhamento metodológico diferente daquele proposto no Curso.

A separação metodológica de língua e fala não se mostra produtiva no raciocínio dialógico. Para o Círculo, o aspecto sistêmico localiza-se no mundo da cultura e é revestido de sentido no ato responsável, que, nesse caso, não coincide necessariamente com a fala. Por que não? Porque a fala se define como ato individual, e o ato responsável se desenha necessariamente como fronteira entre vivência e domínios da cultura e, portanto, é também social; singular, de natureza subjetiva, mas obrigatoriamente social.

Esse é o mesmo motivo pelo qual o Círculo também não se subscreve às perspectivas de língua e linguagem que Bakhtin/Volochínov (1999) chama de subjetivistas individualistas. $\mathrm{O}$ autor não nega o caráter sistêmico da língua, assim como também não nega sua manifestação singular, individual. Entretanto, não adere à ideia de língua como expressão do indivíduo, porque isso faria crer que ela está no interior dele e apenas se externalizaria na fala/escrita, contrariando a articulação de domínios da cultura tão cara para a orientação dialógica. Para Voloshinov (1988),

[...] a língua não é nem uma dádiva de Deus nem da natureza. É o produto da atividade coletiva do homem e em todos os elementos reflete e refrata a organização tanto econômica quanto sociopolitica da sociedade que a levantou. (VOLOSHINOV, 1988, p. 101 - destaque da edição consultada; tradução nossa).

Fica evidente que língua, desse ponto de vista, não se resume a um sistema de relações intrínsecas nem à manifestação individual da linguagem verbal, mas resulta da atividade coletiva humana. Eis aí dois planos imbricados desenhando a fronteira de domínios: há uma dimensão obrigatoriamente coletiva, assim como há também a necessária atualização singular em ato.

Tendo como fundamento epistêmico a noção de ato responsável atualizando fronteiras entre vivência e domínios da cultura, procede a proposta de implicação do semiótico e do ideológico (BAKHTIN/VOLOCHÍNOV, 1999). Ao focar tais fronteiras como o lugar do fenômeno enunciativo, dito de outra maneira, ao reivindicar para o fenômeno enunciativo o 
status de ato responsável, Bakhtin e o Círculo evocam a um só tempo tanto a estabilidade e tendência à permanência do que é próprio do mundo da cultura quanto à instabilidade e à singularidade do que é próprio da vivência subjetiva sem, no entanto, cair nem no objetivismo abstrato da separação língua/fala, nem no individualismo que desvincula o ser que (se) enuncia do arranjo coletivo que o traveste de sentido. É por isso que, dialogando com a noção saussuriana de signo linguístico, Bakhtin/Volochínov pondera:

Os signos só podem aparecer em um terreno interindividual. Ainda assim, trata-se de um terreno que não pode ser chamado de "natural" no sentido usual da palavra: não basta colocar face a face dois homo sapiens quaisquer para que os signos se constituam. É fundamental que esses dois indivíduos estejam socialmente organizados, que formem um grupo (uma unidade social): só assim um sistema de signos pode constituir-se. (BAKHTIN/VOLOCHÍNOV, 1999, p. 35 - destaques da edição consultada).

Com essa afirmação, Bakhtin/Volochínov descarta a proposta metodológica de tratamento preponderante de relações intrassistêmicas. Evidentemente, o sistema de signos não é refutado. Porém, a organização social e, portanto, a ideologia que agrupa indivíduos numa coletividade necessariamente integra o sistema. Integra de que modo? Seguindo a esteira da inspiração kantiana, aqui cabe um diálogo com o conceito de sociação cunhado por Simmel (2006).

O sociólogo alemão, na tarefa de construir um objeto para a Sociologia, reconhece na sociabilidade um caráter agregador que não resulta da mera conjunção de indivíduos/individualidades, mas da conjunção de conteúdos (materiais) e formas de vida social, que dão sentido à interação entre indivíduos. Para Simmel (2006), a fome, o amor, a religiosidade etc. constituem matérias e motivações que impulsionam a vida, mas que em si mesmas não têm natureza social. A partir do momento que esses elementos fomentam a relação de convívio entre seres humanos, aí são referendados como sociais. Assim, o sociólogo articula conteúdo e forma da sociabilidade para a definição do aspecto fundamental da organização de sociedades: a sociação.

Defino assim, simultaneamente, como conteúdo e matéria da sociação, tudo o que existe nos indivíduos e nos lugares concretos de toda realidade histórica como impulso, interesse, finalidade, tendência, condicionamento psíquico e 
movimento nos indivíduos - tudo o que está presente nele de modo a engendrar ou mediatizar os efeitos sobre os outros, ou a receber esses efeitos dos outros. [...] A sociação é, portanto, a forma (que se realiza de inúmeras maneiras distintas) na qual os indivíduos, em razão de seus interesses - sensoriais, ideais, momentâneos, duradouros, conscientes, inconscientes, movidos pela causalidade ou teleologicamente determinados - se desenvolvem conjuntamente em direção a uma unidade no seio da qual esses interesses se realizam. Esses interesses [...] formam a base da sociedade humana. (SIMMEL, 2006, p. 60-61).

Tomar a sociação como condição de um grupo social implica reconhecer que as condições de arranjo coletivo não resultam meramente de conteúdos materiais, mas dos valores projetados sobre tais conteúdos. O que interessa destacar aqui é a interdependência entre língua/linguagem e tal projeção de valor, que integra sociação e semiotização. Novamente de acordo com Bakhtin/Volochínov (1999),

Um signo não existe apenas como parte de uma realidade; ele também reflete e refrata uma outra. Ele pode distorcer essa realidade, ser-lhe fiel, ou apreendê-la de um ponto de vista específico etc. Todo signo está sujeito aos critérios de avaliação ideológica (isto é: se é verdadeiro, falso, concreto, justificado, bom etc.). O domínio do ideológico coincide com o domínio dos signos: são mutuamente correspondentes. Ali onde o signo se encontra, encontra-se também o ideológico. Tudo que é ideológico possui um valor semiótico. (p. 32 - destaque da edição consultada).

É possível articular, assim, sociação e semiotização, uma vez que em ambos a ideologia projeta valor social (sentido) sobre conteúdos materiais. Isso significa dizer que qualquer organização coletiva e construção simbólico-semiótica (preponderantemente, mas não exclusivamente verbal) necessariamente se retroalimentam. Para que haja signo é preciso que haja grupo, assim como para que haja grupo, é necessário que haja referencial ideológico, que não se constrói fora do universo dos signos. Neste ponto, é mister recuperar qual seja a definição de ideologia que perpassa o conjunto da obra de Bakhtin e o Círculo. Segundo Voloshinov (1988, p. 113), ideologia "é a totalidade de reflexões e refrações no cérebro humano da realidade social e natural, tal como expressa e fixada pelo homem na palavra, 
desenho, diagrama ou outra forma de signo" (VOLOSHINOV, 1988:113 - destaques da edição consultada; tradução nossa). Daí a afirmação de que "tudo que é ideológico é um signo. Sem signos não existe ideologia" (BAKHTIN/VOLOCHÍNOV, 1999, p. 31 - destaque da edição consultada). E por conta dessa imbricação entende-se que sociação é, ao mesmo tempo, condição e fruto da semiotização.

Sendo assim, destacam-se duas premissas que sustentam o dispositivo analítico aqui proposto: 1) língua, na condição de sistema de signos ideológicos, é um construto sociocultural; 2) língua e sociação são interdependentes. No caso da questão vernacular brasileira, não há como dissociar a construção da brasilidade - sociação que tem desenhado as sociedades brasileiras possíveis - e língua portuguesa - língua em que se têm dado as relações sociais validadas pelos desdobramentos históricos como brasileiras. Afinal, as relações que antecederam à colonização - que se realizavam na heterogeneidade linguística, étnica, cultural etc. - não tinham, necessariamente, a perspectiva de unidade geopolítica. A discursivização possibilitada pela colonização, especialmente a colonização linguística (MARIANI, 2004), deu novo rumo tanto à história que se construiu no espaço, quanto à língua que gradativamente passou a figurar como preponderante nas relações sociais estabelecidas no que se construiu como Brasil. Para o exame do funcionamento dessa articulação língua/sociação, sugere-se, ainda, breve reflexão sobre como o discurso, flagrado em manifestações enunciativas concretas - atos responsáveis -, funciona como vetor semântico que interpela a palavra (léxico) e fomenta memórias (índice de sociação).

\subsection{Palavra, discursos, memórias: delimitando o dispositivo analítico}

Retomando a discussão de Simmel (2006), em particular suas considerações acerca do pertencimento grupal do indivíduo, destaca-se o valor do legado cultural que alimenta a sociação. De acordo com o sociólogo, o legado é condição para que o indivíduo seja interpelado como sujeito pertencente a um grupo, a uma sociedade. Interessa aqui em particular não o aspecto biológico desse legado, mas sim o ideológico. 
Mas não está em questão somente a hereditariedade em sentido puramente biológico. Também os elementos espirituais que se objetivaram em palavras e conhecimentos, em inclinações afetivas e normas de vontade e juizo, e que penetraram o indivíduo como tradições conscientes e inconscientes, fazem isso de maneira tanto mais segura e universal quanto mais consolidada e evidente elas tenham crescido dentro do espírito de uma sociedade que se desenvolveu ao longo do tempo - isto é, quanto mais antigas forem as tradições. (SIMMEL, 2006, p. 43 - destaques nossos).

Parece evidente que a palavra, o afeto, o juízo, desse ponto de vista, não se restringem à expressividade individual, mas podem alçar o status de legado cultural objetivo e, portanto, referencial ideológico que fomenta o agrupamento social. No raciocínio dialógico, especialmente tomando como base os textos da maturidade intelectual de Bakhtin, há indicações de como o funcionamento da linguagem constrói e mobiliza esse status. Novamente citam-se as palavras do pensador russo:

As ciências do espírito; seu objeto não é um mais dois "espíritos" (o que é estudado e o que estuda, que não devem fundir-se em um só espírito). O verdadeiro objeto é a inter-relação e a interação dos "espíritos". A tentativa de compreender a interação com a palavra do outro por meio da psicanálise e do "inconsciente coletivo". Aquilo que os psicólogos [...] descobrem existiu algum dia; manteve-se não no inconsciente (ainda que no coletivo), mas se consolidou na memória das línguas, dos gêneros, dos rituais; daí ele penetra nos discursos e nos sonhos [...] dos homens (BAKHTIN, 2003b, p. 380 - aspas da edição consultada; destaques nossos).

E também:

As tradições culturais e literárias (inclusive as mais antigas) se conservam e vivem não na memória individual e subjetiva de um homem isolado em algum "psiquismo" coletivo, mas nas formas objetivas da própria cultura (inclusive nas formas linguísticas e verbais), e nesse sentido elas são intersubjetivas e interindividuais (consequentemente, também sociais); daí elas chegam às obras literárias, às vezes quase passando por cima da memória individual subjetiva dos autores. (BAKHTIN, 2010b, p. 354 - aspas da edição consultada; destaques nossos).

Nesses dois fragmentos, estão metonimizadas questões acerca da objetivação da palavra e da consolidação de uma memória da língua que se coadunam com a perspectiva de sociação e legado recuperada em Simmel (2006). 
A questão da memória da língua e da objetivação das formas linguísticas esbarra na estabilidade do significado, daquilo que, de algum modo, permanece estável na língua. Estável, porém não estanque. A dimensão do significado, de acordo com Bakhtin (2003b), não se confunde com os sentidos construídos na dinâmica da comunicação discursiva: "o significado está excluído do diálogo, mas abstraído dele de modo deliberado e convencional. Nele existe uma potência de sentido" (p. 381 - destaque da edição consultada). Essa potência de sentido, entre outros aspectos, é condição para que as formas linguísticas não figurem como elementos vazios apenas veiculadores de sentido e também para que o fluxo da cadeia comunicativa não figure como caos discursivo, mas encadeamento de enunciados, responsavelmente assinados. A comunicação discursiva não se dá desordenadamente, mas atualiza-se a partir daquilo que é mobilizado dessa potência de sentido. E essa mobilização não consiste de mero preenchimento de sentido de formas linguísticas. Antes, consiste também da ativação de parte do que está latente na forma linguística. Em outro ensaio, o pensador russo já pontuara:

[...] a emoção, o juízo de valor, a expressão são estranhos à palavra da língua e surgem unicamente no processo de seu emprego vivo em um enunciado concreto. Em si mesmo, o significado de uma palavra (sem referência à realidade concreta) é extra-emocional [...] Quando escolhemos as palavras no processo de construção de um enunciado, nem de longe as tomamos sempre do sistema da língua em sua forma neutra, lexicográfica. Costumamos tirá-las de outros enunciados e antes de tudo de enunciados congêneres com o nosso (BAKHTIN, 2003a, p. 292 - destaque da edição consultada).

Se, por um lado, a virtualidade do significado é livre de expressão entoativa, por outro, o significado se abstrai do diálogo, que não prescinde de entoação. Isso permite ponderar que o conjunto de mobilizações das formas linguísticas em enunciados concretos, em atos responsáveis, estabiliza nas formas verbais também valor ideológico, que é reorganizado e reacentuado no processo de construção de sentido, e isso participa da gênese, consolidação e manutenção de sociação. Aqui importa retornar à questão da relação palavra/discurso no desenho do legado cultural e da memória. 
Reconhecendo a distinção entre memória subjetiva e memória objetiva (BAKHTIN, 2010b, p. 354; AMORIM, 2009b), o desenho de fronteiras entre vivência e domínios da cultura na performance de atos éticos responsáveis parece mobilizar a memória do sujeito, isto é, seu repertório linguístico - que envolve a ideologia - e cultural como indivíduo membro de um grupo, e a memória da língua, do gênero por meio do qual o sujeito (se) enuncia, do ritual social em que se enquadra, enfim, do legado ideológico que provoca a centelha da sociação. Daí o estabelecimento de um jogo de memórias.

Para se construir a memória subjetiva é preciso que o indivíduo integre um grupo e, para isso, esse indivíduo precisa mobilizar elementos da memória objetiva cultural. Neste artigo, destaca-se especialmente o modo como a memória da língua confere estatuto de sujeito ao indivíduo e, assim, atua na construção de sociedade. Movimentar a cadeia comunicativa discursiva, na permanente tarefa responsível - responsável por seus atos e responsivo aos atos dos outros - (SOBRAL, 2005, $\mathrm{p}$. 20, 21), envolve, então, a performance de ato ético que mobiliza um jogo de memórias: a partir do repertório cultural do grupo, constrói-se a condição de sujeito singular pela constante atualização da linguagem.

Assim, parece pertinente afirmar que a memória da língua, aquela memória objetiva das formas linguísticas e verbais, define-se pelos valores constitutivos e mantenedores de potência de sentido viabilizados pela estabilidade do significado. Mas, se o significado se abstrai do diálogo, é preciso admitir que a memória da língua é gerada e mantida pelo jogo que estabelece com a memória subjetiva daqueles que movimentam a cadeia comunicativa.

\section{A palavra em atos: decisões metodológicas}

Como pontuado alhures (MAGALHÃES, 2012), se o vocábulo botocudo (e variantes) sinaliza pela forma uma convergência linguística, pelos discursos que mobiliza na contemporaneidade aponta para a distinção de diferentes vernáculos. Seu esmaecimento no registro lexicográfico lusitano de hoje e sua presença no registro brasileiro mostram que a palavra atualiza o jogo de memórias de maneiras diferentes nas duas sociedades. Entretanto, a gênese da palavra notadamente de 
base ideológica lusitana imprime em seu significado certo valor que, de algum modo, participa do legado cultural nela objetivado. Pela tensão daí decorrente, seleciona-se este vocábulo - botocudo - como mote para o procedimento analítico da relação entre léxico, os discursos que dão vida às palavras e a sociação neles implicada.

A leitura-análise ora proposta busca traços da estabilidade linguística a partir da palavra tomada em atos para interpretação do impacto gerado na sua potencialidade semântica nos dias de hoje em vernáculo brasileiro. Isso significa dizer que cada registro é considerado em sua dimensão enunciativa, inclusive o registro lexicográfico. Assim, conforme anunciado no título deste artigo, a questão - como a memória da língua portuguesa no Brasil atualiza valores sociais que fomentam possibilidades de significação sociocultural do Brasil? - será respondida no tratamento da palavra, dos discursos e do jogo de memórias, e o estudo segue o seguinte percurso:

1) Descrição do verbete botocudo na edição digital do Grande Dicionário Houaiss da língua portuguesa (INSTITUTO ANTÔNIO HOUAISS DE LEXICOGRAFIA, 2012) a fim de resgatar, pelo trabalho lexicográfico, sua formação, etimologia e primeiro registro (a saber, um poema árcade lusitano do século XVIII. Para este artigo, foi possível apenas o acesso on-line à transcrição da edição francesa do século XIX: CRUZ E SILVA, 1817). Esse dicionário foi selecionado por apresentar, em seus verbetes, índices do trabalho lexicográfico como, por exemplo, a fonte utilizada para datação do vocábulo;

2) Breve análise da formação da palavra para identificar o ponto de vista de processamento semântico na gênese do vocábulo;

3) Cotejo do primeiro registro do vocábulo com registros em outros atos de duas esferas diferentes: política - Carta Régia (BRASIL, 1808) - e jornalística - editorial do Correio Braziliense que versa sobre essa Carta Régia (BRAZIL, 1808), ambos datados do século XIX, para descrição do valor linguístico (que do ponto de vista dialógico implica também valor ideológico) em estabilização (significado que se abstrai do diálogo, dos sentidos atualizados em atos);

4) Cotejo do vocábulo nesses atos com acepções do verbete no dicionário selecionado para interpretação de como o jogo 
de memórias fomenta a potencialidade semântica objetivada no vocábulo botocudo no português brasileiro contemporâneo.

\title{
3 Botocudo em quatro atos: lexicográfico, literário, político e jornalístico
}

Olhar para a palavra a partir do verbete do dicionário não significa olhar a palavra em estado de dicionário. A leitura aqui desenvolvida rastreia o ato de registro lexicográfico, que implica trabalho (ato ético) com a palavra. Para esta análise, interessam, sobretudo, as acepções de adjetivo, já que são esses os usos recuperados nos enunciados cotejados.

\begin{abstract}
Botocudo: substantivo masculino ( c1764) 1 etnol denominação dada pelos portugueses a indígena pertencente a grupos de diversas filiações linguísticas e regiões geográficas por usarem botoques labiais e auriculares; eram assim chamados os caingangues e os xoclengues de Santa Catarina [...] etnm.br.: Botocudo. 2 ling família linguística do tronco macrojê. Adjetivo. relativo a botocudo (acp. 1 e 2) ou aos botocudos ('grupos indígenas'). Adjetivo e substantivo masculino pej. 3 (1875-1888) que ou quem é inimigo das boas maneiras; rude, incivil. 4 que ou quem mora na roça; caipira. Etimologia: botoque + -udo, com valor desde sempre pejorativo, por 'bárbaro, rude, selvagem'. Sinônímia e Variantes como adj.s.m.: ver sinonímia de caipira. Antonímia como adj.s.m.: ver antonímia de caipira (INSTITUTO ANTÔNIO HOUAISS DE LEXICOGRAFIA, 2012 - negritos nossos; demais destaques da edição consultada).
\end{abstract}

O vocábulo data do século XVIII e é cunhado a partir da analogia com botoque. Sua gênese é marcada pela circunscrição cultural recuperada no próprio processo de associação de um elemento com outro de ordem díspar e pela postura valorativa flagrada na seleção do sufixo. Quanto à analogia, a ideia-base - botoque - remete ao orifício de pipas e tonéis em que se armazenavam azeite, por exemplo, e/ou às rolhas que vedavam tal orifício (CUNHA, 2010). No âmbito do Brasil do século XVIII, é possível imaginar que se trata de uma referência europeia, estranha àqueles que já habitavam as terras que passaram a significar brasil. Relacionar botoque a adereços utilizados por determinadas tribos autóctones implica um olhar estrangeiro, alteritário, que evidencia fronteiras de sociações: aqueles que fazem a analogia entre botoque e adereço indígena não cons- 
tituem um grupo social com aqueles que são denominados a partir de tal analogia, e a palavra que daí deriva estabiliza valores europeus, objetivando parte do legado ideológico. Quanto ao sufixo -udo, de origem latina, há de se considerar que: a) forma substantivos e adjetivos e b) transmite certa depreciação (COUTINHO, 2005, p. 171). Linguisticamente, portanto, é gerado um nome que denomina, classifica determinado grupo de indígenas que se diferencia de outros que não utilizam tais apetrechos. Em função de adjetivo, nos termos de Castilho (2010, p. 532), funciona como adjetivo de verificação gentílico.

Ressalta-se, porém, que, ao cunhar botocudo, o lusitano registra na língua não apenas o processo cognitivo de analogia, revelando o referencial de sociação, mas também o estranhamento em relação àquilo que é pelo novo vocábulo designado. A acepção número 1 do verbete registra o referencial de processamento cognitivo, e a indicação etimológica dá pistas do valor social da palavra que corroborará sua potencialidade semântica. Mas, se como ponderara Saussure (1995), o falante não conhece senão a sincronia da língua, de que modo os valores flagrados na gênese da palavra podem se consolidar na memória objetiva da língua? Para responder essa questão, é preciso atentar para os discursos que vivificam o vocábulo em enunciados concretos, em atos éticos.

O primeiro registro do vocábulo, conforme indicado no dicionário, é o poema herói-cômico de António Diniz da Cruz e Silva - "O hyssope" -, de 1764. Escrito no estilo épico de Os Lusíadas - estilo grandiloquente - versa sobre conteúdo banal. O poema trata de uma questão de cerimonial entre o bispo de Elvas e o deão da respectiva Sé e ridiculariza os valores feudais, a ostentação da aristocracia e os abusos praticados pelo clero. Literariamente, o enunciado poético opera com a tensão entre os constrangimentos estéticos vigentes na esfera (domínio artístico garantido pelo tratamento estético épico grandiloquente) e a responsabilidade do dizer inerente à atualização da linguagem (domínio ético, da vivência, mobilizado pelo conteúdo banal que contrasta com o acabamento estético refinado), resultando, nesse caso, em um gênero híbrido - herói-cômico - construído sobre o sarcasmo e a ironia. Sarcasmo e ironia são, então, a chave para o processamento semântico desse enunciado. 
A palavra em análise neste artigo aparece no Canto V, no momento em que o "afrancesamento" entre os lusitanos é desdenhado, sendo a língua francesa comparada à "língua dos selvagens Boticudos"2": "Pois aqui, em segredo, lhe descubro,/ Que o Francês, para mim, o mesmo monta,/Que a língua dos selvagens Boticudos." (CRUZ E SILVA, 1817, s/p - destaque da edição consultada). Ora, o sarcasmo só se realiza pelo cotejo semântico do refinamento social projetado no imaginário acerca da cultura francesa com o tom pejorativo mobilizado na palavra cunhada - boticudo. Por essa atualização da palavra, à designação lusitana para alguns indígenas, adjunge-se o valor semântico-ideológico de incivilizado, inculto, não refinado. Assim, abre-se a possibilidade de permeação semântica: o que a princípio cunha um adjetivo de verificação gentílico (que diz respeito à determinada tribo, etnia, povo) agora é supostamente alterado em adjetivo predicativo qualificador polar (culto/inculto, por exemplo). A grafia em maiúsculo parece sustentar a primeira leitura (de verificação gentílico). Porém, a possibilidade de significação sarcástica que se recupera da oposição francês/boticudo, selvagem, donde culto, civilizado/inculto, incivilizado, sugere a passagem do adjetivo para a categoria de predicativo qualificador (CASTINHO, 2010, p. 526).

O segundo e o terceiro atos dos quais se destaca a palavra são a Carta Régia de 13 de maio de 1808, em que D. João VI manda fazer guerra aos índios que resistiam à ordem social lusitana (BRASIL, 1808), e um dos textos editoriais da edição de outubro de 1808 do Correio Braziliense, em que Hipólito da Costa comenta sobre a Carta Régia que manda fazer guerra aos índios (BRAZIL, 1808). Ambos os textos já foram examinados por Magalhães (2012). Para a presente discussão, cabe apenas cotejar como a tensão entre memórias subjetivas alimenta a potencialidade semântica do vocábulo.

Na Carta Régia, lê-se: “Sendo-me presente as graves queixas que da Capitania de Minas Geraes tèm subido á minha real presença, sobre as invasões que diariamente estão praticando os indios Botocudos, antropophagos, em diversas e muito distantes partes da mesma Capitania (...)". Nesse caso, botocudos

2 Está fora do escopo deste artigo a análise das formas variantes boticudo e botecudo. e antropófagos aparecem coordenados em aposição. Numa primeira leitura, configuram adjetivos que classificam os índios aos quais de fato o rei se refere, ou seja, dentre os índios em 
território brasileiro, o rei se refere àqueles que utilizam certos apetrechos (botoques) e que praticam a antropofagia. Trata-se, portanto, de adjetivos de verificação em função adnominal.

Em um dos textos editoriais da edição de outubro de 1808 do Correio Braziliense, Hipólito da Costa comenta sobre a Carta Régia que manda fazer guerra aos índios, e a palavra é tomada em tom irônico (MAGALHÃES, 2012). Entendendo que a ironia se faz, necessariamente, sobre dois valores antagônicos, o tom pejorativo mantém-se como base, como condição para a reacentuação irônica proposta pelo editor. Desse texto do Correio, recuperam-se os seguintes sintagmas: índios Botecudos e NaçaO dos Botecudos (BRAZIL, 1808, p. 421). Se a apresentação formal dos sintagmas parece corroborar botecudo como adjetivo de verificação gentílico, novamente a possibilidade de performance irônica é garantida pela permeação semântica que desloca o vocábulo para a categoria de predicativo qualificador. Assim, a tensão gerada entre os domínios da cultura por meio de atos éticos alimenta a potencialidade semântica do vocábulo e consolida uma memória objetiva estabilizada, aparentemente, não tanto pela analogia com botoque, mas principalmente pelo juízo, tom pejorativo flagrante desde a gênese da palavra.

Voltando ao verbete do dicionário, nota-se que o registro etimológico indica: desde sempre pejorativo. As acepções 3 (já com datação do final do século XIX) e 4 já não sinalizam mais a relação com botoque, mas guardam o ponto de vista lusitano pela manutenção do tom pejorativo. Isso sugere que, da dinâmica de memórias subjetivas, do jogo de sentidos flagrado nos discursos que interpelam os enunciados, resulta, no significado de botocudo, uma potencialidade semântica, sobretudo, predicativa qualificadora. As acepções 1 e 2 restringem-se a jargões e mantêm de certo modo objetivados o processo cognitivo de associação com botoque e, provavelmente, o valor semântico denominativo. Porém, nas demais acepções - aquelas que visam registrar a palavra nos domínios não específicos de uso -, a analogia inicial esmaece, e o valor ideológico - de estranhamento do outro - se mantém. Registra-se na memória da língua o tom que, de um modo ou de outro, como demonstrado nos enunciados destacados, permanece invariante. $\mathrm{O}$ referencial 
de valor que define o que é considerado civilizado, culto, o que é considerado boas maneiras, urbano etc, mantém-se. $\mathrm{O}$ juízo sobre o que difere disso mantém-se. É o valor ideológico que constitui e habita a memória objetiva dessa forma linguística e viabiliza a permeação semântica e ulterior suposto deslocamento do adjetivo de uma subcategoria semântica (de verificação) para outra (predicativa). Curiosamente, como já destacado anteriormente (MAGALHÃES, 2012), esse vocábulo, que registra um tom valorativo lusitano, não integra o repertório da edição digital do dicionário português da Editora Porto. Botocudo parece um flagrante de tensões e alteridades constitutivas do vernáculo brasileiro e, por isso, é pertinente dizer que a tarefa lexicográfica registra o potencial semântico constituinte da memória objetiva da forma linguística que valora o vocábulo como integrante de um sistema de signos ideológicos e revelador de fronteiras de sociação.

\section{Considerações finais}

Ao fim desta breve reflexão, é possível afirmar que a memória da língua se constitui da potencialidade semântica provida pelo significado e se altera pelo jogo de memórias. Isso porque nenhum enunciado parte de um vácuo semântico nem ideológico, mas recupera, da estabilização provida pela memória da língua, elementos que podem ser reacentuados por meio do que o repertório da memória subjetiva daqueles implicados no enunciado permite.

Aqui há uma contribuição que merece destaque. $\mathrm{O}$ tratamento dialógico-discursivo que, em geral, ocupa-se do estudo do sentido pode também fomentar estudos acerca do significado. A análise de como o jogo de memórias subjetivas pode corroborar a potencialidade semântica lexical e, assim, participar da consolidação da memória da língua dá pistas para estudos focados na relação entre língua e sociedade, articulando tanto aquilo que permanece estável no sistema de signos ideológicos quanto aquilo que é singular nos enunciados. 


\section{REFERÊNCIAS}

AMORIM, M. Para uma filosofia do ato: "válido e inserido no contexto". In: BRAIT, B. (org) Bakhtin: dialogismo e polifonia. São Paulo: Contexto, 2009a, p. 17-44.

AMORIM, M. Memória do objeto - uma transposição bakhtiniana e algumas questões para a educação. Bakhtiniana. Revista de Estudos do Discurso. São Paulo, v. 1, n. 1, p. 8-22, $1^{\circ}$ semestre 2009b.

BAKHTIN, M. M. Os gêneros do discurso. Estética da criação verbal. Trad. Paulo Bezerra. 4.ed. São Paulo: Martins Fontes, 2003a, p. 261-306.

BAKHTIN, M. M. Apontamentos 1970-1971. Estética da criação verbal. Trad. Paulo Bezerra. 4.ed. São Paulo: Martins Fontes, 2003b, p. 367-392.

BAKHTIN, M. M. Para uma filosofia do ato responsável. São Carlos: Pedro \& João Editores, 2010a.

BAKHTIN, M. M. Formas de Tempo e de Cronotopo no Romance (Ensaios de poética histórica). Questões de literatura e de estética (A teoria do romance). Trad. Aurora Fornoni Bernardini et al. 6. ed. São Paulo: Hucitec Editora, 2010b, p. 211-362.

BAKHTIN, M. M./ VOLOCHINOV, V. N. Marxismo e Filosofia da Linguagem. Problemas fundamentais do método sociológico na Ciência da Linguagem. Trad. Michel Lahud e Yara Frateschi Vieira. 9. ed. São Paulo: Hucitec, 1999.

BRAIT, B. (org.) Bakhtin e o Círculo. São Paulo: Contexto, 2009a. BRAIT, B. (org.) Bakhtin - dialogismo e polifonia. São Paulo: Contexto, 2009b.

BRAIT, B.; CAMPOS, M. I. B. Da Rússia czarista à web. BRAIT, B. (org). Bakhtin e o Círculo. São Paulo: Contexto, 2009, p. 15-30. BRAIT, B.; MAGALHÃES, A. S. (orgs) Dialogismo: teoria e(m) prática. São Paulo: Terracota Editora, 2014.

BRASIL. Carta Régia, de 13 de maio de 1808. Manda fazer guerra aos indios Botocudos. BRASIL. Leis etc. Colecção das Leis do Brazil de 1808. Rio de Janeiro: Imprensa Nacional, 1891, p. 37-41. Disponível em: <http://www.planalto.gov.br/ ccivil_03/ revista/Rev_18/CartaRegia_1305.htm> Acesso em:30 nov. 2011. 
BRAZIL. Correio Braziliense. Vol. I, Londres: W. Lewis, Paternoster.Row, out. 1808. Miscellanea, p. 420-425. Disponível em: <http://www.brasiliana.usp.br/bbd/ handle/1918/060000005\#page/1/mode/1up> Acesso em: 17 set. 2010.

CASTILHO, A. T. de. Nova gramática do português brasileiro. São Paulo: Contexto, 2010.

COUTINHO, I. de L. Gramática Histórica. 7. ed. 19. Reimpressão. Rio de Janeiro: Ao Livro Técnico, 2005.

CRUZ E SILVA, A. D. O Hyssope. Paris: Oficina de A. Bobée, 1817. Disponível em: <http://www.literaturabrasileira.ufsc. br/_documents/0006-02949.html> Acesso em: 26 jan. 2012.

CUNHA, A. G. da. Dicionário etimológico da língua portuguesa. 4. ed. Rio de Janeiro: Lexikon, 2010.

EMERSON, C. Os cem primeiros anos de Mikhail Bakhtin. Trad. Pedro Jorgensen Jr. Rio de Janeiro: DIFEL, 2003.

INSTITUTO ANTÔNIO HOUAISS DE LEXICOGRAFIA (Brasil). Grande Dicionário Houaiss da língua portuguesa. Rio de Janeiro, 2012. Disponível em: <http://houaiss.uol.com.br/>. Acesso em: 02 out. 2014.

KANT, I. Crítica da razão pura. Trad. Alex Marins. São Paulo: Martin Claret, 2004. [Tradução feita com base na segunda edição revista e ampliada de 1787]

MAGALHÃES, A. S. Políticas linguísticas e historicização do Brasil: a escrita na construção vernacular. Gragoatá (UFF), v. 32, p. 99-116, 2012.

MAGALHÃES, A. S. Escritas da brasilidade: subjetivação e política lusófona na documentação vernacular. DELTA. Documentação de Estudos em Linguística Teórica e Aplicada (PUCSP), v. 29, p. 1-27, 2013.

MARIANI, B. Colonização linguística. Línguas, política e religião no Brasil (séculos XVI a XVIII) e nos Estados Unidos da América (século XVIII). Campinas: Pontes, 2004.

PORTO EDITORA. Dicionário da Lingua Portuguesa. Disponível em: http://www. infopedia.pt/lingua-portuguesa/botecudo. Acesso em: 2 dezembro 2011.

SAUSSURE, F. de. Curso de Linguística Geral. Trad. Antônio Chelini et al. 20. ed. São Paulo: Cultrix, 1995. 
SIMMEL, G. Questões fundamentais da sociologia: indivíduo e sociedade. Trad. Pedro Caldas. Rio de Janeiro: Jorge Zahar Ed., 2006.

SOBRAL, A. Ato/atividade e evento. In: BRAIT, B. (org.) Bakhtin: conceitos-chave. São Paulo: Contexto, 2005, p. 11-36.

VOLOSHINOV, V. N. [M. M. BAKHTIN]. What is language? In: SHUKMAN, A. (org) Bakhtin school papers. Russian Poetics in Translation. Somerton: Old School House, 1988, p. 93-113.

\section{Abstract \\ The word, the discourses and the dynamics of memories}

The aim of this article is to demonstrate, through a brief analysis of the semiotic-dialogic processing of a word from its genesis until its register as a dictionary entry, how the word can drive discourses which sustain and which are sustained by values constitutive of the social group which mobilizes the language and, thus, it can inject into the memory of the language not only linguistic forms, but also judgement and worldview. From a dialogic point of view of language, it is argued that language, as a system of ideological signs, is a sociocultural construct and, therefore, it is interdependent of the process of formation of social groups. The analysis developed shows that the lexicon can, sometimes, signalize, through the forms, linguistic convergence and, other times, it can show, through the discourses it mobilizes nowadays, a distinction of vernaculars.

Key-words: lexicon; Bakhtinian studies; ethics, political and aesthetic dimension of language. 